Available online at

http://journal.ugm.ac.id/ifnp
INDONESIAN FOOD AND NUTRITION PROCRESS

Indonesian Food and Nutrition Progress, 2017, Vol. 14, Issue 2

\title{
Review: Extensive Potentiality of Selected Tropical Fruits from Indonesia
}

\author{
Andriati Ningrum ${ }^{1)}$, Matthias Schreiner ${ }^{2)}$ \\ ${ }^{1)}$ Department of Food and Agricultural Product Technology, Faculty of Agricultural Technology, Universitas \\ Gadjah Mada, Jalan Flora No. 1 55281, Yogyakarta, Indonesia \\ ${ }^{2)}$ Department of Food Sciences and Technology, University of Natural Resources and Life Sciences (BOKU), \\ Muthgasse 18, 1190 Vienna, Austria \\ ${ }^{*}$ Corresponding author, e-mail: andriati_ningrum@yahoo.com
}

Received 20 September 2017; Accepted 29 November 2017; Published Online 30 November 2017

\begin{abstract}
Indonesia has several biodiversities including tropical fruits. The consumption of tropical fruits is increasing as this source can be used as a healthy source of several bioactive compounds to prevent severalnoncommunicable diseases. Tropical fruits are commonly used for the production of several food products e.g. juice, jams, jellies, cookies and other products. The utilization of by product of tropical fruits have not been developed and promoted. Although, several bioactive compounds are still present in tropical fruits by product. This concept called as avalorization of by product to increase the economical value of several by product. The purpose of this review isto promote several selected Indonesian tropical fruit and also to promote the potency of a by-product of tropical fruits in valorization concept.
\end{abstract}

Keywords: valorization, tropical fruits, bioactive compounds, non-communicable diseases

\section{Introduction}

The consumption of fruit is not just for a taste and also consumer's personal preference, but it has become a concern of a health due to the fruit nutrient contents. Several essential nutrients, Fruits feature considerable amounts of micronutrients such as vitamins, minerals, fibers and other secondary metabolites as bioactive compounds (Metafa \& Economou, 2013). This evidence showed the importance of several nutrients in fruits for human health. Consumption fruits rich in several bioactive compounds associated with a reduction of several non-communicable diseases such as certain types of cancer, inflammation cardiovascular diseases, cataracts, macular degeneration, and also neurodegenerative disease (Clerici, 2011). Recently, consumption of tropical fruit is increasing observed based on domestic and also international market trends due to growing recognition of its nutritional and also therapeutic value (Clerici, 2011).

In Indonesia, several underexploited native and exotic fruit species are of potential interest to the agroindustry and a possible future source of income for the local population (Woerdenbag \& Kayser, 2014). These exotic fruits represent an opportunity for local growers, especially to gain access to special markets where consumers emphasize on exotic characteristic and nutrients presence for preventing several noncommunicable diseases. On the other hand, there is also a potential use of these exotic and tropical fruit pulps and their by-products to isolate specific phytochemicals as bioactive compounds for application in nutraceutical 
supplements, dietary additives, new food and pharmaceutical products, contributing to therecovery of agro-industrial process waste. That way, the identification and quantification of several bioactive compounds in pulps and by-product of exotic fruit are very important to proveand contribute theirpotential health benefits in human nutrition.

The processing of several tropical fruits will produce the mass of by-products that may approach or even exceed the corresponding valuable product which is affecting the benefical value of economics for growing tropical crops. Forexample, by-products resulting from the processing of several tropical fruits like papaya, pineapple, and mango represent approximately 10-60\% fruits. Fruits by-products can make up of peels, rinds, seeds and unused flesh (pomace) that are generated by different steps of the industrial process and usuallyhave no further usage and commonly wasted or discarded. The added value of processing tropical crops could be improved by developing higher value use for their by-product. It has been reported that the by-products in several tropical fruits contain high amountof various healthbeneficialsubstances that can be extracted to provide nutraceuticals. The utilization of the entire plant tissue can have economic benefits to producers and beneficial impact to the environment, leading to a greater diversity of products. Several investigationshas been performed to determine the bioactive compounds in tropical fruits (Dey, Chakraborty, Jain, Sharma, \& Kuhad, 2016; Elleuch et al., 2011; Morais et al., 2014). Taking into account that the potential of compounds present in pulps and by-products of tropical fruits as bioactive compounds for non-communicable diseases, this review aimed to compare major bioactive compounds found in several tropical fruits in Indonesia. The purpose of the review is to describe several tropical fruits with their nutritional values and also to provide selected information to promote several by-product from selected tropical fruits.

\section{Tamarind (Tamarindus indica)}

One of tropical fruit called Tamarind (Tamarindus indica), can be found in several regions especially in Africa and Asia. The most valuable part of the plant is its pulp. The utilization of the Tamarind's pulp varies for the seasoning application, flavor enhancement in several traditional foods and also as the main ingredient in juices and beverages. The refreshing tamarind drinks are popular in many countries around the world, though there are many different recipes. Sometimes, the juice obtained from the fruit pulp is mixed with wood ash to neutralize the sour taste of tartaric acid in tamarind. However, the most common method is to add sugar to make acid drink more pleasing. Sometimes pulp is fermented into an alcoholic beverage (Caluwe and Damme, 2010).

Typically, tamarind contains $20.6 \%$ water, $3.1 \%$ protein, $0.4 \%$ fat, $70.8 \%$ carbohydrate, $3 \%$ fibre and $2.1 \%$ ash. The pulp has a low water content and alow level of carbohydrates and minerals. Nevertheless, the proximate content of tamarind pulp depends on local variety. Protein content in tamarind pulp, unfortunately, has been shown to be poorly digested and utilized in vivo as compared with proteins in coconut meat that are extensively digested and efficiently utilized by mammals in vivo. For fatty acid content, tamarind fruit pulp is relatively poor in oil ( $25.3 \mathrm{~kg}$ of crude lipid), greenish yellow in color and liquid at room temperature. Saponification values of the oil are relatively high indicating that it contains a high proportion of low molecular weight fatty acids. In regard to essential fatty acids, the fruit pulp contains low linoleic acid $(3.42 \mathrm{mg} / \mathrm{g}$ 
dry weight) and even lower amounts of linolenic acid $(0.21 \mathrm{mg} / \mathrm{g}$ dry weight). The tamarind pulp is also a rich source of several macro and micro elements, including ahigh amount of copper, manganese, zinc, calcium and phosphorous. Other bioactive components in tamarind pulp e.g. Vitamin B, Carotenoids and also Vitamin C (Caluwé \& Damme, 2010).

The seed part contains tannin and other matters that have not been utilized so far in thefood industryThe soaking and boiling process of tamarind kernel powder can lead to the making of textile and paper industries. On the other hand, the kernel part can be utilized as a source of proteins and they are alsorich in some essential minerals. The kernel part also contains pectin where the pectin can be utilized as food additives to form gels. Tamarind seed is also can be used as araw material used in the manufacture of polysaccharide (jellose), adhesive and tannin. The tamarind kernels contained $46-48 \%$ of a gel-forming substance. This polysaccharide (pectin) with carbohydrate character and jelly forming properties named "jellose" and has been used for stabilizer in ice cream, mayonnaise,cheese and as an ingredient or agent in a number of pharmaceutical products. Flour from the seed may be made into cake and bread. Roasted seeds are claimed to be superior to groundnut in flavor. On the other hand, tamarind seeds may be adopted as an inexpensive alternative protein source to alleviate malnutrition in protein among traditional people living in developing countries (Caluwé \& Damme, 2010).

The other part of this plant e.g.leaves and flower can be consumed as vegetables and several traditional diseases. Like other leafy vegetables, tamarind leaves are a fair source of vitamin C, carotenoids, mineral e.g. $\mathrm{P}, \mathrm{K}, \mathrm{Ca}$ and $\mathrm{Mg}$. Where those components have antioxidant, anti-inflammatory, anti- microbial and antifungal activities (Caluwé \& Damme, 2010).

Tamarind is rich in polyphenolic compounds that are unfortunately can inhibit iron absorption by forming iron complexes in the intestine, making dietary iron less available for absorption (Caluwé \& Damme, 2010). Tamarind containsmany kind of polyphenols dominated by proanthocyanidins in various forms. The phenolic compounds in tamarin are easy to breakdown during the storage and also influenced by the irradiation preservation. The glycosylated phenolic compounds can break to several compounds e.g. procyanidin trimer, tetramer, pentamer, hexamer that are present in tamarind ((Badr, 2006)). Epicatechin is a phenolic compound found in tamarind that has antioxidant activities to prevent several noncommunicable diseases.

Several antioxidative compounds were also isolated and identified from the seed coats; phenolic antioxidants. This antioxidant may be used to increase theshelf life of food products and improve the stability of lipids and lipid-containing foods by preventing loss of sensory and nutritional quality by preventing lipid peroxidation. These compounds may also find a place as food additives though furtherstudy is needed to evaluate their effectiveness within food matrices (Caluwé \& Damme, 2010). Tamarind seed coats exhibit good antioxidant activity against linoleic acid emulsion system and the values were lower and higher than the synthetic antioxidant e.g. BHA (Butyl Hydroxy Annisol). Phenolic plant compounds may have many biological effects in terms of health promotion. The important protective effect is areduction of oxidative damage, mediated by lipid peroxidation which in living systems is strongly associated with mutagenesis, carcinogenesis, aging and atherosclerosis. The antioxidative activity of tamarind seed was also investigated where 
the ethanol and ethyl acetate extracts prepared from the seed coat exhibited antioxidative activity. This suggested that tamarind seed coats, a by-product of the tamarind gum industry, may have a potentiallylow-cost source of antioxidant. For the leaf extracts also showed antioxidant activity in vivo. Tamarind also has hypolipemic activity in vivo. Tamarind extracts can diminish the risk of atherosclerosis development in humans.

\section{Roselle (Hibiscus sabdariffa)}

Hibiscus sabdariffa is one of traditional fruit contains several bioactive compounds. This plant, commonly known in English as roselle or red sorrel, is widely grown in Central and West Africa, South East Asia and elsewhere. The roselle extracts are used in fold medicine against many complaints that include high blood pressure, liver diseases, and fever. The red anthocyanin pigments in the calyces are used as food coloring agents. The swollen calyces are the part of the plant of commercial interest as they are rich sources of Vitamin C, phytochemicals and also used for several purposes. Several products like jellies and jams made from roselle which is said to be taste like an acidic plume jam. Several bioactive compounds are found in roselle e,g. anthocyanins, carotenoids, riboflavin, thiamine, niacin, ascorbic, malic and hibiscus acids (Jung \& Joo, 2013).

\section{Tamarillo (Solanum betaceum)}

Tamarillo is one of the tropical fruit known as tomato tree that belongs to the Solanaceae family (Carolina L Leivas et al., 2016)The distribution of the fruitvaries from Colombia, Malaysia, Indonesia,New Zealand and other Southeast Asia countries. It is an exotic fruit with high level of micronutrients and bioactive components (Erdmann et al., 2015; Mertz, Brat, Caris-veyrat, \& Gunata, 2010). Several micronutrients e.g. Vitamins
B6, Vitamin C, and Vitamin E and the levels of trace elements as iron, magnesium, copper and potassium contain in Tamarillo, where several bioactive compounds such as anthocyanins, carotenoids, and flavonoids also can be found in this fruit (Castro-vargas, Benelli, Ferreira, \& Parada-alfonso, 2013; Erdmann et al., 2016; Mertz et al., 2010)). This fruits is also interesting to be further investigated for their edible, juicy, tastyand consumed fresh or used in various side dishes such as sauces, jellies, ice creams, juices, etc.

\section{Star Fruit (Averrhoa carambola)}

Starfruit (Averrhoa carambola), is one of the tropical fruit which is consumed either fresh or served as juice (Bhat, Binti, Ching, Karim, \& Min, 2011). This plant belongs to Oxalidaceae family and cultivated in various other Asian countries and in tropical areas of America including Bazil. Several pharmacological activities have been reported for adifferent part such as fruit, leaves, and stem (Carolina Lopes Leivas, lacomini, \& Cordeiro, 2016). The mature fruit is star shaped, sweet, juicy and golden yellowcoloured. Starfruits are used for preparing fruit salads or made into jellies and preserves.

Several bioactive compounds are found in Starfruit which is usually used as a traditional medicine to relieve pain from indigestion, hypoglycemic effects and also to reduce fever. This fruit also contains high dietary fiber which leads to several investigations for dietary fiber contain in this fruit. Leivas et al. (2016) described a pectin from starfruit formed by a type I rhamnogalacturonan containing arabinan and type I arabinogalactan as the neutral side chains. Herein, we describe the chemical structure of a substituted galacturonan extracted from A. carambola fruits and report the findings on its antinociceptive and antiinflammatory effects (Carolina Lopes Leivas et al., 2016). 


\section{Conclusion}

Several tropical fruits described in this text have been appreciated in Indonesia. Nowadays, there are increasing interest tastes for sometropical fruits. The significant increase of those tropical fruits and also their products e.g. juices forces the scientific community to characterize several important physicochemical properties the fruits. In this context, several bioactive compounds the fruits are essential for several applications in food industry. This paper reviewed someimportant bioactive compounds of fruits which are essential for many applications of several exotic fruits.

\section{Acknowledgment}

Authors gratefully acknowledge Loreal UNESCO For Women in Science Fellowship 2016 and Ernst March Grant Scholarship for supporting this research

\section{References}

Badr, H. M. 2006. Effect of gamma radiation and cold storage on chemical and organoleptic properties and microbiological status of liquid egg white and yolk. Food Chemistry, 97, 285-293. http://doi.org/10.1016/j.foodchem.2005. 05.004

Bhat, R., Binti, S., Ching, H., Karim, A. A., and Min, L. 2011. Quality attributes of starfruit ( Averrhoa carambola L .) juice treated with ultraviolet radiation. Food Chemistry, 127(2), 641-644. http://doi.org/10.1016/j.foodchem.2011. 01.042

Caluwé, E. De, \& Damme, and P. Van. 2010. Tamarindus indica L . - A review of traditional uses, phytochemistry and pharmacology. Africa Focus, 23(1), 5383.

Castro-vargas, H. I., Benelli, P., Ferreira, S. R. S., and Parada-alfonso, F. 2013. The Journal of Supercritical Fluids
Supercritical fluid extracts from tamarillo (Solanum betaceum Sendtn) epicarp and its application as protectors against lipid oxidation of cooked beef meat. The Journal of Supercritical Fluids, 76, 17-23. http://doi.org/10.1016/j.supflu.2012.10. 006

Clerici, M. T. P. S. 2011. Nutritional bioactive compounds and technological aspects of minor fruits grown in Brazil. FRIN, 44(7), 1658-1670.

http://doi.org/10.1016/j.foodres.2011.04 .020

Dey, T. B., Chakraborty, S., Jain, K. K., Sharma, A., and Kuhad, R. C. 2016. Trends in Food Science \& Technology Antioxidant phenolics and their microbial production by submerged and solid state fermentation process: A review. Trends in Food Science \& Technology, 53, 60-74. http://doi.org/10.1016/j.tifs.2016.04.007

Elleuch, M., Bedigian, D., Roiseux, O., Besbes, S., Blecker, C., and Attia, H. 2011. Dietary fibre and fibre-rich by-products of food processing: Characterisation, technological functionality and commercial applications: A review. Food Chemistry, 124(2), 411-421. http://doi.org/10.1016/j.foodchem.2010. 06.077

Erdmann, G., Rita, C., Fernanda, M., Werner, D. P., Hatsuko, C., lacomini, M., and Cordeiro, L. M. C. 2015. Structure of an arabinogalactan from the edible tropical fruit tamarillo (Solanum betaceum ) and its antinociceptive activity. Carbohydrate Polymers, 116(72896), 300-306. http://doi.org/10.1016/j.carbpol.2014.03 .032

Erdmann, G., Simas-tosin, F. F., lacomini, M., Albert, P., Gorin, J., and Cordeiro, L. M. C. 2016. Rheological behavior of high methoxyl pectin from the pulp of tamarillo fruit (Solanum betaceum ). Carbohydrate Polymers, 139, 125-130. 
http://doi.org/10.1016/j.carbpol.2015.11 .067

Jung, E., and Joo, N. 2013. Roselle ( Hibiscus sabdariffa $\mathrm{L}$.) and soybean oil effects on quality characteristics of pork patties studied by response surface methodology. MESC, 94(3), 391-401. http://doi.org/10.1016/j.meatsci.2013.02 .008

Leivas, C. L., lacomini, M., and Cordeiro, L. M. C. 2016. Pectic type II arabinogalactans from starfruit ( Averrhoa carambola L . ). Food Chemistry, 199, 252-257. http://doi.org/10.1016/j.foodchem.2015. 12.020

Leivas, C. L., Nascimento, L. F., Barros, W. M., Santos, A. R. S., lacomini, M., and Cordeiro, L. M. C. 2016. International Journal of Biological Macromolecules Substituted galacturonan from starfruit: Chemical structure and antinociceptive and anti-inflammatory effects. International Journal of Biological Macromolecules, 84, 295-300. http://doi.org/10.1016/j.ijbiomac.2015.1 2.034

Mertz, C., Brat, P., Caris-veyrat, C., and Gunata, Z. 2010. Characterization and thermal lability of carotenoids and vitamin C of tamarillo fruit (Solanum betaceum Cav .). Food Chemistry, 119(2), 653-659.

http://doi.org/10.1016/j.foodchem.2009. 07.009

Metafa, M. and Economou, A. 2013. Chemometrical development and comprehensive validation of a solid phase microextraction/gas chromatography-mass spectrometry methodology for the determination of important free and bound primary aromatics in Greek wines. Journal of Chromatography. A, 1305, 244-58. http://doi.org/10.1016/j.chroma.2013.07 .005

Morais, L., Altina, E., Figueiredo, T. De, Maria, N., Silva, P., Gusmao, I., and Gomes, C. L. 2014. Quantification of bioactive compounds in pulps and by-products of tropical fruits from Brazil. Food Chemistry, 143, 398-404. http://doi.org/10.1016/j.foodchem.2013. 08.001

Woerdenbag, H. J. and Kayser, O. 2014. Jamu: Indonesian traditional herbal medicine towards rational phytopharmacological use. Perspectives in Medicine, 4(2), 51-73. http://doi.org/10.1016/j.hermed.2014.01 .002 